\title{
Breakage behaviour of sand particles in point-load compression
}

\author{
WANYING WANG* and MATTHEW R. COOP†
}

\begin{abstract}
Single-particle uniaxial compression tests are generally conducted for sands by compressing a grain between two flat platens. However, previous work has shown that due to the complex morphology of natural sands the nature of their contacts with the loading platens can influence their strength. A custom-built apparatus was therefore built to apply point loading to sand particles. Using a high-speed camera, typical failure modes were observed, which showed less variability than those seen in platenmounted tests with most undergoing some form of splitting. The particle strength under point loading also tended to be lower than for platen loading, and again with less variability. If the point-loading tests were compared with platen-loading tests for a similar splitting breakage mode, then the strength distributions were very similar. A possible explanation is that the platen-loading tests that underwent a splitting failure were the more angular particles, and so the effect of stress concentration might be similar to that for the point-loading tests.
\end{abstract}

KEYWORDS: laboratory tests; particle crushing/crushability; particle-scale behaviour

ICE Publishing: all rights reserved

\section{NOTATION}

$d$ particle size

$d_{2}$ intermediate dimension of SCC (smallest circumscribed cuboid) of a particle

$d_{3}$ minor dimension of SCC (smallest circumscribed cuboid) of a particle

$f$ tensile stress

$f_{0} \quad$ characteristic strengh

$N$ force

$p_{\mathrm{s}} \quad$ survival probability of a particle experiencing a tensile stress $f$

$\sigma_{\mathrm{f}}$ maximum tensile stress

\section{INTRODUCTION}

The single-particle compression test is a widely used method, in which a sand particle is compressed between two flat polished platens to study the breakage behaviour and strength of a single particle (Lee, 1992; McDowell \& Bolton, 1998; Nakata et al., 1999, 2001a, 2001b; Pitchumani et al., 2004; Antonyuk et al., 2005; Cavarretta et al., 2010; Cavarretta \& O'Sullivan, 2012). Previous studies have investigated the breakage behaviour of sands both of single particles as well as in standard laboratory 'element' tests. Cavarretta \& O’Sullivan (2012) proposed five damage stages for single-particle loading: initial rotation, damage, elastic response, fragmentation and crushing. Wang \& Coop (2016) emphasised that in single-particle crushing tests, the particle angularity at the contact surfaces with the platens played a controlling role since stress concentrations affect the particle strength and failure mode.

Computational simulations, including the finite-element method (FEM) and discrete element method (DEM) have provided other ways to investigate the breakage mechanisms of single particles. For example, Tapias et al. (2015) proposed

Manuscript received 13 November 2017; first decision 20 December 2017; accepted 3 January 2018.

Published online at www.geotechniqueletters.com on 21 February 2018.

*Guangdong University of Technology; formerly City University of Hong Kong, Hong Kong.

†University College London; formerly City University of Hong Kong, Hong Kong. a discrete model to simulate particle crushing under uniaxial compression. They determined two breakage mechanisms: local abrasion at the contact region, mainly attributed to shear stress, and global splitting in tension, when the grain splits into two equal parts along a main crack along the loading axis.

Russell \& Muir Wood (2009) carried out an analytical simulation of a point-load test on an elastic sphere. Their results showed that the maximum intrinsic stress occurred just below the contact centre, at a ratio of the distance from the centre, $r$, to the radius $R$ of 0.91 , which agreed well with the conclusion of Chau \& Wei (1999). In this location, the ratio between the second, deviatoric stress invariant and the first stress invariant reached a maximum and so this should be the location of crack initiation.

However, these DEM and FEM simulations are hampered by the complex nature of a non-conforming contact between flat platens and a nominally spherical particle, in which the contact size and contact stress distribution are functions of the changing load. Cavarretta \& O'Sullivan (2012) highlighted that a natural irregular sand particle also usually has three points at the bottom platen and one at the top if it is placed at rest on a horizontal plane, that is in total four contact points. The stress fields will depend on the locations of those contacts and how they evolve with loading, especially if the particle rotates under the applied load. Therefore, point-load tests should give more consistent data than platen-loading tests. Point-load tests have been widely used to investigate the strength of larger brittle geomaterials such as rock (e.g. Hiramatsu \& Oka, 1966) and ballast (e.g. Koohmishi \& Palassi, 2016). Due to the small size of sand particles and their rapid breakage process, it is hard to conduct point-load tests on sands at the particle scale, while also studying the breakage mechanisms. In this study, a novel apparatus was built that enabled single particles to be compressed under point loads. Fifty-three point-load tests were carried out, comparing with similar existing platen-loading tests.

\section{APPARATUS AND MATERIALS}

Figure 1 shows the apparatus, which in the basic arrangement is similar to that of Wang \& Coop (2016) for 


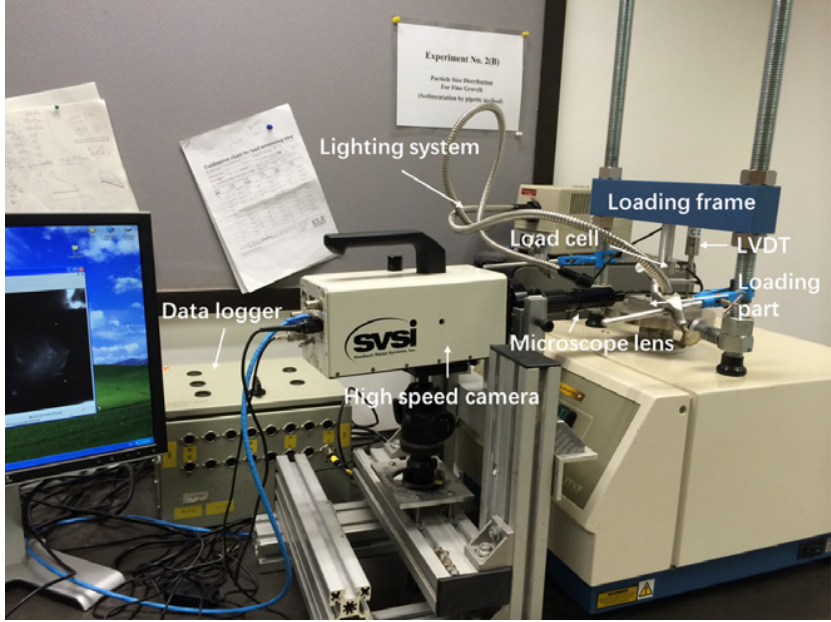

Fig. 1. Apparatus for point-load tests on single sand particles

platen-loading tests, with a loading frame providing the uniaxial load. The high-speed camera had a capacity of 2000 frames/second, which, combined with a microscope lens for up to $16 \times$ magnification, recorded the rapid breakage processes. A fibre-optic lighting system was used to provide a concentrated light source because of the low exposure times resulting from the high speed of the camera. In addition, image processing software (Sony Vegas) was used to improve the image quality. A load cell with a capacity of $800 \mathrm{~N}$ was placed above the upper particleloading mount and a linearly variable differential transformer (LVDT) was placed below the load cell, thereby avoiding the compliance of the load cell affecting the accuracy of the displacement measurements.

Figure 2 shows the point-loading mounts. The radius of curvature of the point ends was $0.2 \mathrm{~mm}$, which was the smallest that was practical to be manufactured while also avoiding excessive damage during loading. Both the upper and lower mounts were also made of stainless steel of high hardness, again to minimise damage and distortion to the tips. Nevertheless, after several tests, the tips were often slightly flattened, leading to an inaccurate curvature, so they were replaced frequently.

It is important to keep the upper and lower contact point precisely aligned, otherwise, the particle could rotate during loading. Therefore, a brass well was used to act as a guide cylinder, allowing both mounts to move freely inside while ensuring perfect alignment. A window allowed the highspeed camera to view the particle. The inner wall was highly polished and covered with lubricant so that any friction between the mounts and the well was negligible. Careful alignment of the system also ensured that there was no, or little, contact between the loading shafts and the cylinder. A small patch of plasticine was used to retain the sand grain on the point of the lower mount before the force was applied. Once the upper mount was in contact with the sand particle, the plasticine did not interfere with the force transmission and just squeezed out.

Leighton Buzzard sand (LBS) of $2 \cdot 36-5 \cdot 00 \mathrm{~mm}$ was tested, the particles tested being selected randomly. They were cleaned by sonic waves before testing and were manipulated with tweezers to avoid contamination of the particle surface.

\section{CRUSHING MODES UNDER POINT LOADING}

Wang \& Coop (2016) conducted single-particle compression tests under platen loading using a similar apparatus and

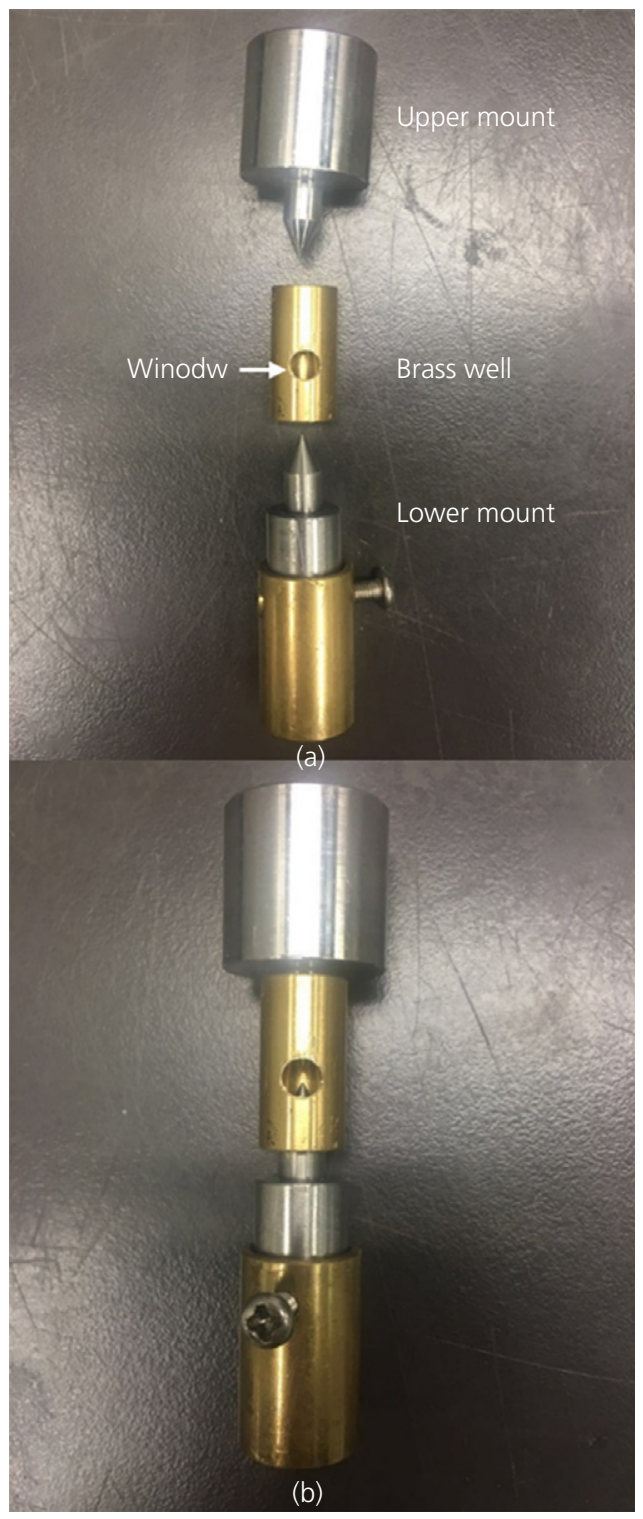

Fig. 2. Mounts for the point-load tests (a) individual parts; (b) assembled mounts

concluded that there were two main breakage modes: splitting and explosive, based on the number of fragments and intensity of the crushing process. For point-loading tests, although the final failure had some variability of intensity, essentially all the particles split into two or three large parts, similar to the splitting mode for the platen-loading tests, and none had the more violent explosive mode accompanied by the creation of multiple fragments. A typical test is illustrated in Fig. 3. A bright region occurred near the loading point in frame (2), indicating a crack starting to initiate here. Then the crack propagated gradually from the edge to the centre, which was a slow process lasting $4.5 \mathrm{~s}$, compared with the final failure that was more rapid and brittle. Finally, a portion of the particle split away rapidly, but very few small chips or fragments were created. In Fig. 4, the relationship between force and displacement for this test is shown, labelling the data points corresponding to each frame in Fig. 3. It can be observed that the crack propagation continued throughout much of the loading process. The force-displacement curve is very much softer for point loading than for platen loading and Fig. 4 includes a forcedisplacement curve for a typical platen-loaded test from Wang \& Coop (2016). 


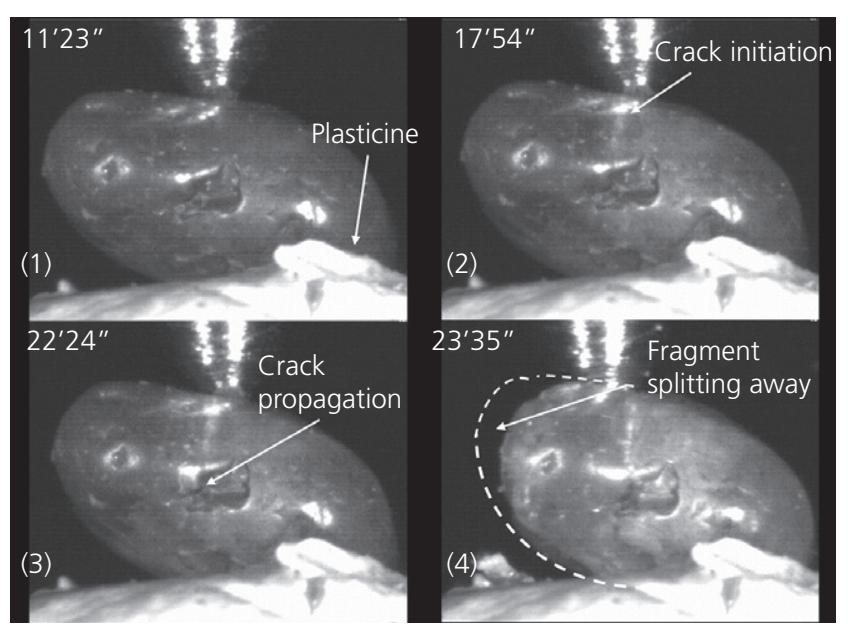

Fig. 3. Failure mode in a typical point-load test

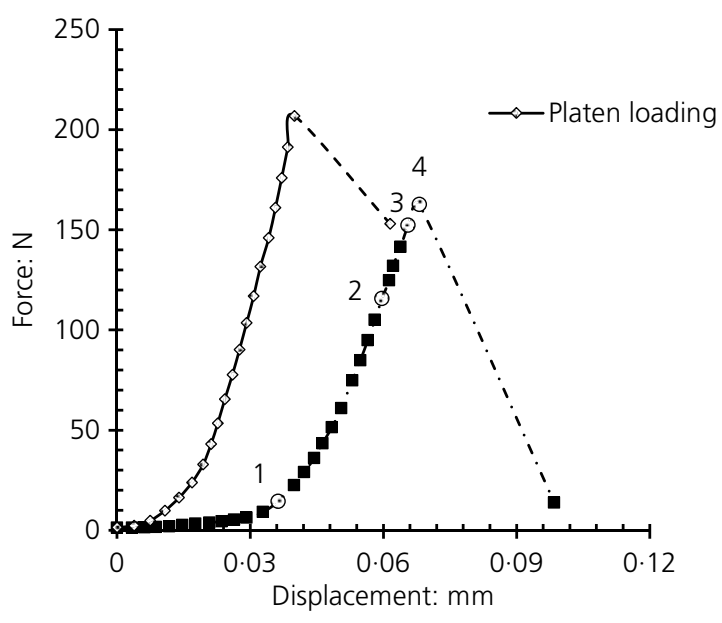

Fig. 4. Relationship between force and displacement of a single particle under point load

Figure 5 presents images of fragments for typical breakage behaviour for point loading. Generally, the two pieces created were relatively intact and the planes of failure quite flat. Lobo-Guerrero \& Vallejo (2006) conducted a series of point-load tests on railway ballast rock samples, coal and a glass bead. The results showed that for the natural materials, the breakage mode was very similar to that seen here, with two to three large fragments along with some minor tiny chips. The glass broke in a rather different mode with multiple tiny fragments, but this may be caused by the different crystalline structures that glass has compared to the quartz sand grains tested here.

\section{A COMPARISON OF PARTICLE STRENGTHS FOR POINT-LOAD AND PLATEN-LOAD TESTS}

Using the formula suggested by Cavarretta (2009), the stress along the loading plane at the peak force was calculated as

$$
\sigma_{\mathrm{f}}=\frac{0 \cdot 225 N}{d^{2} / 4}=\frac{0 \cdot 9 N}{d^{2}}
$$

where $N$ is the force and $d$ the particle size from $d=\sqrt{d_{2} d_{3}}$. The actual cross-sectional area at the location of the loading points is almost impossible to measure in practice, particularly since the particles would often shift location slightly at the start of loading, adjusting to the loading location and the local contact geometry. Therefore, a geometrical average value of $d_{2}$ and $d_{3}$ was still used as an approximation, as in the platen-loading tests, where $d_{2}$ and $d_{3}$ are the intermediate and minor dimensions, measured with callipers prior to the tests. Care was taken to place the particles in the same orientation as they were in rest state when on a flat surface, and the point loads were located across the largest dimension in the vertical direction.

Figure 6(a) shows the comparison of particle strength data between point loading and the previously published platenloading data. As expected, the survival probability curve for platen loading is above that for point loading because of the lower stress concentration near the loading region for platen loading and as well as there being four contact points in a platen test rather than two. Therefore, it is possible that more energy could be stored inside the particle to create more fracture surface generation, which would be associated with some of the particles undergoing the explosive mode for particles under platen loading. For the platen-loading tests, $36 \%$ of the particles underwent an explosive mode (Wang \& Coop, 2016).

The characteristic stress of particles under point loading is $29 \cdot 5 \mathrm{~N}$, roughly $14 \%$ less than that for the platen-loading tests with a stress of $33.6 \mathrm{~N}$. However, in terms of Weibull moduli $m$, the difference between the two testing conditions is small (Fig. 6(b)). For lower strengths the two distributions are

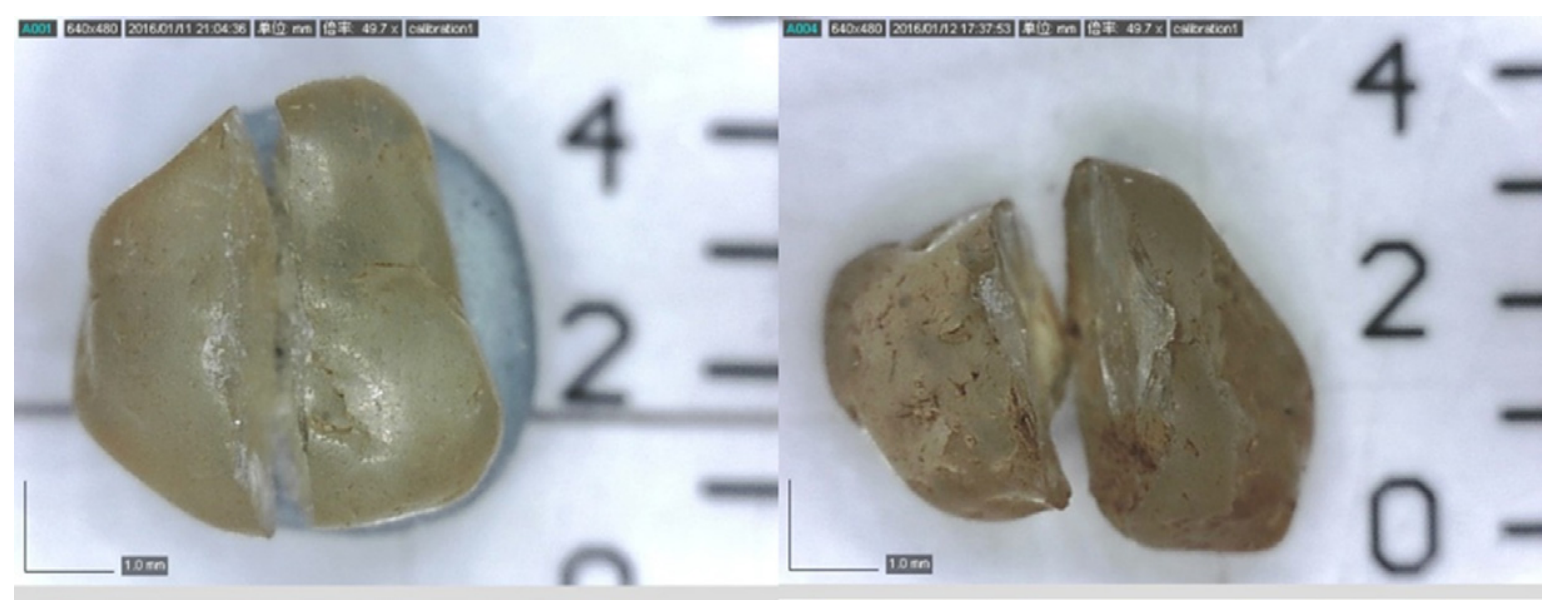

(a) (b)

Fig. 5. Two examples of top views of crushed particles after point-load tests: (a) example a; (b) example b 


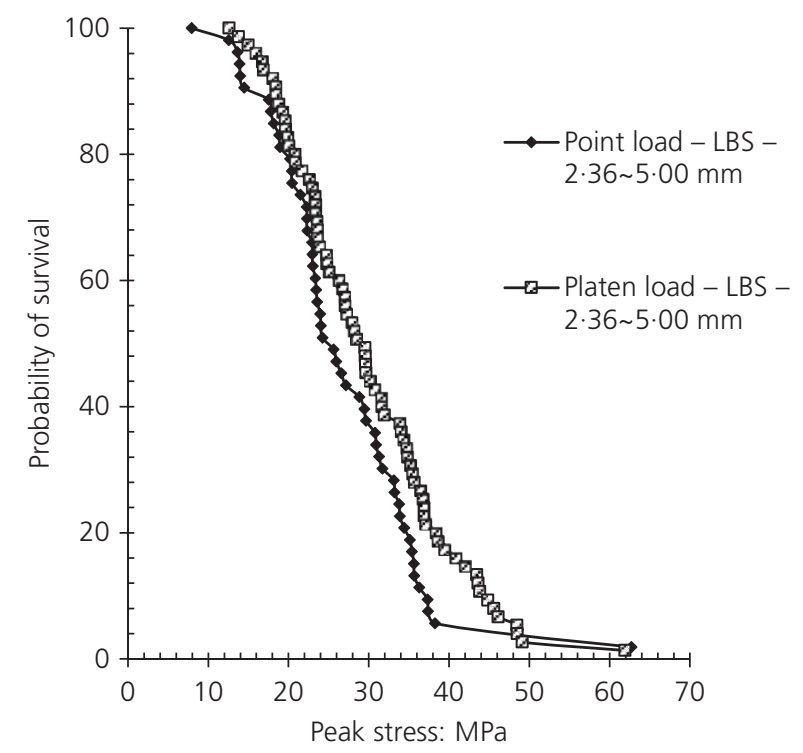

(a)

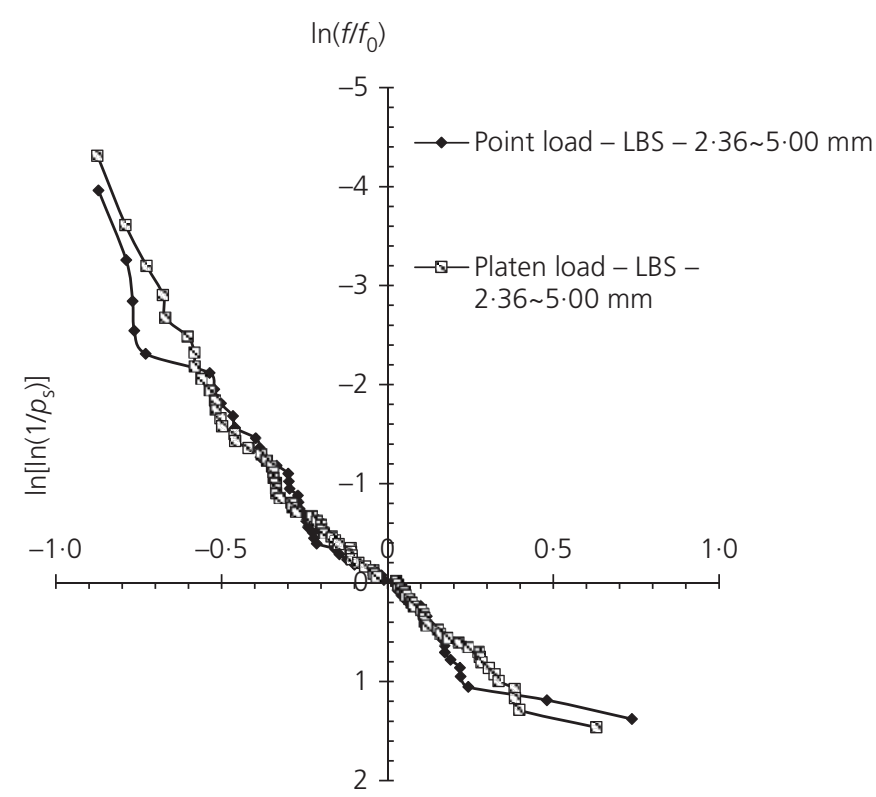

(b)

Fig. 6. Comparison of (a) peak stress (b) Weibull moduli for point loading and platen loading (Data for platen-load tests from Wang \& Coop, 2016.)

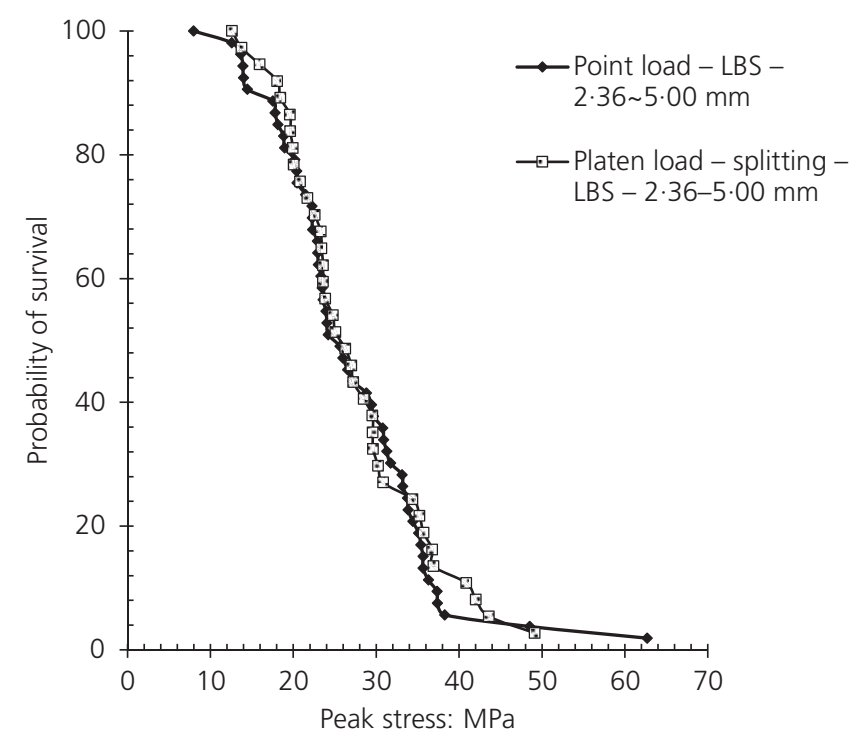

Fig. 7. Comparison of the peak stress distributions for point-loading and platen-loading tests where particles underwent a splitting failure (Data for platen-load tests from Wang \& Coop, 2016.)

similar, but the platen-loading tests diverge in the higher strength region where the failures tend to be more frequently of an explosive nature, Wang \& Coop (2016) having found that these are the particles with more rounded contacts with the platens, and hence less stress concentration, which therefore fail with a much higher stored energy.

The stress concentration at the contact point is clearly the cause of the lower characteristic stress for point loading, which is similar to the reason of the lower strengths measured for single particles broken in the splitting mode in platen-loading tests (Wang \& Coop, 2016). Figure 7 therefore shows a comparison of the peak stress distribution under point and platen loading, only considering those that failed in a splitting breakage mode for the latter. The difference between these two datasets is then insignificant.

\section{CONCLUSION}

Quartz sand particles with size of 2.36-5.00 $\mathrm{mm}$ were crushed under point loading in a novel compression test apparatus, using a high-speed camera to investigate the breakage behaviour. In contrast to conventional platen-loading tests, only a splitting mode was observed and particles tended to split into two or three large pieces at failure.

The characteristic strength was slightly higher for platen loading, and it is concluded that this is because the use of point loading eliminated the possibility of the more violent explosive mode as the particle shape no longer played a significant role in the strength. The point loading gave an almost identical strength distribution to particles that had failed by a splitting mode in platen loading, suggesting that the effects of stress concentration due to the point loading used here and those arising from the angularity of particles in platen-loading tests is similar.

The elimination of the more violent explosive mode does give a slightly more consistent strength measurement, having reduced particle shape effects, but it has to be admitted that the point-loading tests are very much more difficult to conduct, both from the point of view of the care and time needed to prepare each one and also the necessity to replace the points very frequently.

\section{ACKNOWLEDGEMENTS}

The study was fully supported by a grant from the Research Grants Council of the Hong Kong Special Administrative Region, China (theme-based research project scheme 'Understanding Debris Flow Mechanisms and Mitigating Risks for a Sustainable Hong Kong' - Project number CityU 8779012).

\section{REFERENCES}

Antonyuk, S., Tomas, J., Heinrich, S. \& Mörl, L. (2005). Breakage behaviour of spherical granulates by compression. Chem. Engng Sci. 60, No. 14, 4031-4044.

Cavarretta, I. (2009) The influence of particle characteristics on the engineering behaviour of granular materials. $\mathrm{PhD}$ thesis, Department of Civil and Environmental Engineering, London, UK. 
Cavarretta, I. \& O'Sullivan, C. (2012). The mechanics of rigid irregular particles subject to uniaxial compression. Géotechnique 62, No. 8, 681-692, http://dx.doi.org/10.1680/geot.10.P.102.

Cavarretta, I., Coop, M. R. \& O'Sullivan, C. (2010). The influence of particle characteristics on the behaviour of coarse grained soils. Géotechnique 60, No. 6, 413-423, http://dx.doi.org/ 10.1680/geot.2010.60.6.413

Chau, K. T. \& Wei, X. X. (1999). Spherically isotropic, elastic spheres subject to diametrical point load strength test. Int. J. Solids Struct. 36, No. 29, 4473-4496.

Hiramatsu, Y. \& Oka, Y. (1966). Determination of tensile strength of rock by compression test of an irregular test piece. Int. J. Rock Mech. Mining Sci. 3, No. 2, 89-99.

Koohmishi, M. \& Palassi, M. (2016). Evaluation of the strength of railway ballast using point load test for various size fractions and particle shapes. Rock Mech. Rock Engng 49, No. 7, 2655-2664.

Lee, D. M. (1992). The angle of friction of granular fills. PhD thesis, University of Cambridge, Engineering Department, Churchill College, Cambridge, UK.

Lobo-Guerrero, S. \& Vallejo, L. E. (2006). Discrete element method analysis of railtrack ballast degradation during cyclic loading. Granular Matter 8, 195-204, https://doi.org/10.1007/s10035006-0006-2.

McDowell, G. R. \& Bolton, M. D. (1998). On the micro mechanics of crushable aggregates. Géotechnique 48, No. 5, 667-679, http://dx.doi.org/10.1680/geot.1998.48.5.667.
Nakata, Y., Hyde, A. F. L., Hyodo, M. \& Murata, H. (1999). A probabilistic approach to sand particle crushing in the triaxial test. Géotechnique 49, No. 5, 567-583, http://dx.doi.org/10.1680/ geot.1999.49.5.567.

Nakata, Y., Hyodo, M., Hyde, A. F. L., Kato, Y. \& Murata, H. (2001a). Microscopic particle crushing of sand subjected to high pressure one-dimensional compression. Soils Found. 41, No. 1, 69-82.

Nakata, Y., Kato, Y., Hyodo, M., Hyde, A. F. L. \& Murata, H. (2001b). One-dimensional compression behaviour of uniformly graded sand related to single particle crushing strength. Soils Found. 41, No. 2, 39-51.

Pitchumani, R., Zhupanska, O., Meesters, G. M. H. \& Scarlett, B. (2004). Measurement and characterization of particle strength using a new robotic compression tester. Powder Technol. 143-144, 56-64, https://doi.org/10.1016/j.powtec. 2004.04.007.

Russell, A. R. \& Muir Wood, D. (2009). Point load tests and strength measurements for brittle spheres. International Journal of Rock Mechanics \& Mining Sciences 46, No. 2, 272-280.

Tapias, M., Alonso, E. E. \& Gili, J. (2015). A particle model for rockfill behaviour. Géotechnique 65, No. 12, 975-994, http://dx.doi.org/10.1680/jgeot.14.P.170.

Wang, W. \& Coop, M. R. (2016). An investigation of breakage behaviour of single sand particles using a high-speed microscope camera. Géotechnique 66, No. 12, 984-998, http://dx.doi.org/ 10.1680/jgeot.15.P.247. 